\title{
Measurement of heterophil antibody and antibodies to EB viral capsid antigen IgG and IgM in suspected cases of infectious mononucleosis
}

\author{
J. M. BLAKE, J. M. B. EDWARDS ${ }^{1}$, W. FletChER, D. A. McSWIGGAN, \\ AND M. S. PEREIRA \\ From the Virus Reference Laboratory ${ }^{1}$, and Epidemiology Research Laboratory, Central Public Health \\ Laboratory, Colindale Avenue, London N9 5HT and the Public Health Laboratory, and Department of \\ Microbiology, Central Middlesex Hospital, Acton Lane, Park Royal, London NW10 7NS
}

SYNOPSIS The EBV IgG titres in acute and convalescent specimens from 97 cases of infectious mononucleosis were compared with titres from acute and convalescent sera from 96 students with illnesses resembling infectious mononucleosis but without heterophil antibody, EB IgM or EB IgG seroconversion; and also with titres from 91 healthy students known to have had EB IgG antibody for at least six months. These titres were related to the titre of the Research Standard A.66/235 for infectious mononucleosis serum prepared by the National Institute for Biological Standards and Control.

Serial sera were tested for heterophil antibody and EBVCA specific IgG and IgM from 61 university students with infectious mononucleosis. The period of persistence of heterophil antibody and EBV IgM after illness was outlined from the results of the tests.

Single sera from 406 patients in hospital or general practice sent to the diagnostic laboratory for heterophil antibody tests were also tested for EBV antibodies without prior knowledge of the heterophil antibody result. The close agreement between heterophil antibody and EBV IgM results is shown. False positive EB IgM results were correlated with the presence of rheumatoid factor.

In 1971 Hampar et al demonstrated by immunoferritin electron microscopy the presence of EB virus IgM in fractions of sera from cases of infectious mononucleosis but not from healthy persons with EB viral capsid antigen (VCA) IgG titres. Banatvala et al (1972) and Schmitz and Scherer (1972) were also able to demonstrate EB virus IgM in cases of infectious mononucleosis by immunofluorescence.

As IgM is the antibody present during acute infection this evidence confirmed the connection between infectious mononucleosis and primary infection with EB virus. This had already been clearly indicated by the work of Niederman et al (1970) in the USA. They studied university student cases of infectious mononucleosis from whom stored pre-illness sera were available. They had found, using the immunofluorescence test for EB viral capsid antigen (VCA) IgG described by

Received for publication 13 January 1976

Henle and Henle (1966), that cases with heterophil antibody positive infectious mononucleosis converted from IgG negative to IgG positive and that no student already positive for EB IgG developed true infectious mononucleosis at a later date. As a result of these findings Evans formulated criteria for the diagnosis of infectious mononucleosis similar to the following:

Clinical

Haematological

Serological
Sore throat, fever, lymphadenopathy

At least $50 \%$ mononuclear cells including $10 \%$ atypical cells

Positive heterophil antibody (Paul Bunnell) test after absorption and fourfold or greater rise in EB viral capsid antibody (IgG)

A similar study reaching similar conclusions was undertaken in the UK between 1969 and 1974 by a group of university health physicians and Public Health Laboratory Service laboratories (University 
Health Physicians, 1971). Using sera from this source and from diagnostic specimens received in the Central Middlesex Hospital laboratory for routine heterophil antibody tests the pattern of specific EBV IgG and IgM and heterophil antibody has been studied in order to:

1 demonstrate the range of EBV IgG titres in acute and convalescent sera from student cases of infectious mononucleosis related to EB virus infection and from cases with similar symptoms but not related to EB infection and to compare these with titres in sera from students who, from previous tests, were known to possess EB antibody and to have been symptomless during the previous six months;

2 show the pattern of disappearance of EBV IgM and heterophil antibody after an attack of infectious mononucleosis; and

3 distinguish between specific EBV IgM staining and false positive staining due to the presence of EBV IgG with rheumatoid factor (anti-IgG macroglobulin) in the same serum.

\section{Serum specimens studied}

GROUP A FROM UNIVERSITY STUDENTS

1 Paired acute and convalescent sera from 193 students with suspected infectious mononucleosis.

2 Pre-illness sera from 166 of these 193. Pre-illness sera were not available from the remaining 27 students but in all of these the acute illness specimens were negative for EB antibodies.

3 The diagnosis of IM was confirmed in 97 of the 193 suspected cases and post-convalescent sera were obtained from 61 of these positive cases.

4 Sera from 91 students taken six months after entry. These students were chosen because their entry sera had been positive for EB IgG. The second sera were titrated to give a normal distribution curve for EB IgG in students who had been healthy and had had EB IgG antibody for at least six months.

GROUP B

Four hundred and six single sera received at the Public Health Laboratory of the Central Middlesex Hospital, London from hospital patients and patients of local medical practitioners for diagnostic heterophil antibody test.

\section{Methods}

Sera were tested for heterophil antibody by horse erythrocyte agglutination (Davidsohn and Henry, 1969) at the Central Middlesex Laboratory, and for EB specific IgG and IgM by the indirect immunofluorescence test at the Virus Reference Laboratory.
The method of Henle (Sumaya et al, 1975) was usect for the IgG test, varied only by using incubation periods of 60 rather than 45 minutes each. A similar: test on a 1 in 8 dilution of whole serum was used fop detecting IgM. Differences were that the source of antigen was HR-1K cells, the serum treatment of antigen was given three hours' incubation to favouff attachment of the macroglobulin antibody, and the conjugate used was a specific anti-human IgM/FITCฏ Results of all these tests were collated at the Epidem iology Research Laboratory.

The first 100 of the group B sera were all tested by means of the monospot test (Ortho Diagnostics. as well as the full heterophil antibody test. The subsequent 306 were initially only screened by monospot test. Only those found positive by monospot were tested by the full heterophil antibody test:o Later all sera showing discordance between EB IgM and monospot tests were tested by the full heterophip antibody test, and EB IgM tests were repeated. -

The techniques of the tests and details of the Wellcome Research Laboratories conjugates and tungsten-halogen illumination system used are described by Edwards and McSwiggan (1974). Alb EB IgM screening tests and all EB IgG titres were compared with a standard serum tested under theo same conditions. This freeze dried serum gis prepared by the National Institute for Biologicab Standards and Control and is called the Reseath Standard A.66/235 for infectious mononucleosis which, in our immunofluorescence system, gives to positive EB IgM test at 1 in 8 and an EB IgG titre of 1 in 256. Titration readings were not taken at the last dilution giving visible fluorescence but at dilution giving medium fluorescence, which lies between the last dilution giving bright fluorescence and the first trace reading. In this way a reading is: chosen equivalent to a $50 \%$ end point, ie, on the steep slope of the dose response curve.

Rheumatoid factor (RF), as detected by the Wellcome Laboratories Rheuma-Wellcotest, occur 8 infrequently and in controls as well as in patients with infectious mononucleosis (Sutton et al, 1974a)응 This factor is an IgM present in the serum directed against human IgG and it provides a three-stepo alternative pathway for the staining of EB vira capsid antigen by specific anti-human IgM fluoreso cent conjugate if EB IgG is also present in the serumn

$$
\begin{aligned}
& \text { EB virus anti-EB anti-IgG anti-IgM N } \\
& \text { in } \longleftarrow \text { virus } \longleftarrow \text { IgM } \longleftarrow \text { fluorescent } \\
& \text { HR1K cells IgG (RF) conjugate }
\end{aligned}
$$

Some sera were therefore tested for the presence of rheumatoid factor by the Wellcome Laboratories? Rheuma-Wellcotest, an agglutination test usingo human IgG-coated latex particles. The technique described by the manufacturers was followed buf 

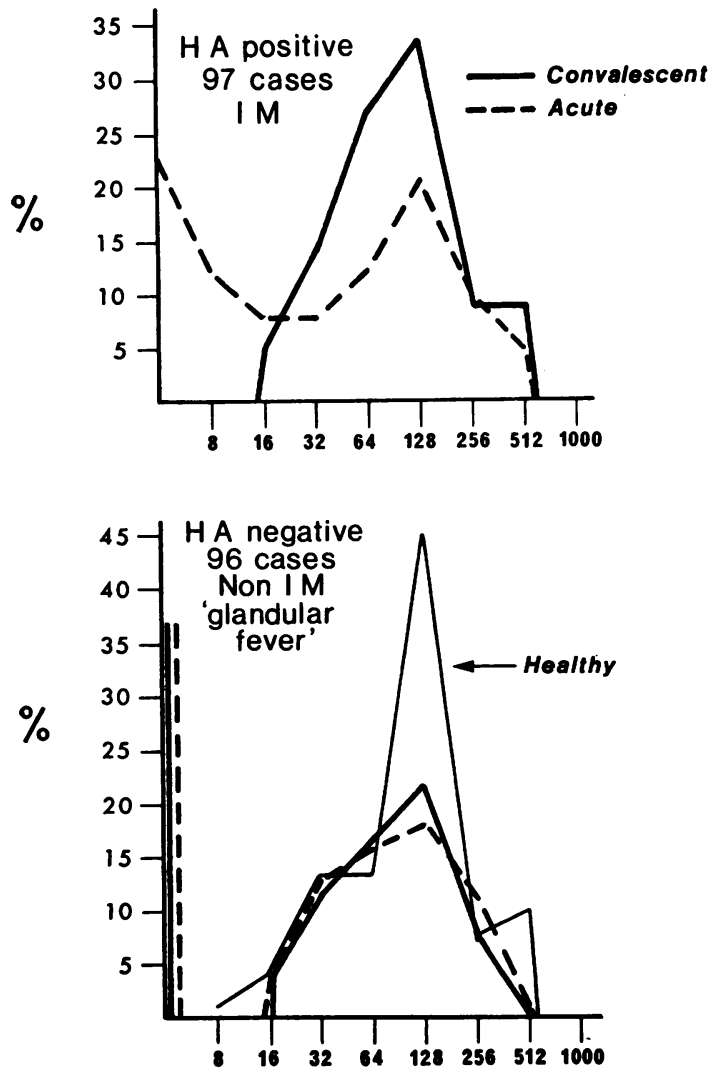

Titre

Fig 1 Distribution curve of $E B$ IgG titres. Above: Acute and convalescent sera from 97 cases with positive $E B$ IgM and heterophil antibody $(H A)$ tests and $E B$ IgG conversion from negative at 1 in 8 in the pre-illness or acute specimen to 1 in 32 or more in the convalescent specimen, ie, true infectious mononucleosis (IM).

Below: Acute and convalescent sera from 96 cases with negative EB IgM and heterophil antibody $(H A)$ tests and no change in EB IgG status between pre-illness and convalescent serum, ie, not infectious mononucleosis (Non-IM). Thirty-six cases remained negative for EB IgG at convalescence and 60 were $E B \operatorname{Ig} G$ positive before illness.

In comparison sera from 91 healthy students taken in May 1971 who were known to have had a positive EB IgG test in October 1970 and no reported illness in the interim.

the serum dilution of 1 in 8 was used as in the immunofluorescence screening tests rather than 1 in 25 , the titre considered of significance for the diagnosis of rheumatoid arthritis. Density gradient fractionation isolates the RF IgM from the anti-EB IgG so that they cannot react together linking the EB antigen with the anti-IgM fluorescent conjugate.
Sera showing positive reactions in the RF test were fractionated on a sucrose density gradient and the fractions were tested for EB IgG and IgM.

In the heterophil antibody test a serum was considered positive when the agglutinating titre of the serum after absorption with guinea-pig kidney suspension was more than four times the titre after absorption with ox-cell suspension. The same Standard serum A.66/235 was used as a control positive serum in each large batch of tests. In this test the Standard gave the following haemagglutination titres with horse erythrocytes: unabsorbed 1 in 1792; after guinea-pig kidney absorption 1 in 1792; after ox-cell absorption less than 1 in 56.

\section{Results}

The results of the EB IgG titres in specimens from group A were plotted to give the distribution curves in figure 1. The upper graph shows the percentages of acute and convalescent sera from 97 cases of true infectious mononucleosis (IM) at each titre from less than 1 in 8 to 1 in 1000. The lower graph shows the percentage of acute and convalescent sera from 96 cases of 'glandular fever' not infectious mononucleosis. Titres of sera from 91 students who had been healthy for 6 months and were known to have had EB positive sera 6 months previously were plotted for comparison.

Figure 2 shows the proportion of positive, weak positive, and negative tests to the total number tested at each period, from pre-illness to postconvalescence on serial sera from 61 students with confirmed infectious mononucleosis. Each of the three tests is charted separately, EB IgG, EB IgM, and heterophil antibody (HA). EB IgG and IgM were negative in all specimens taken before onset of the illness, and the convalescent specimens were all EB IgG positive at a titre of at least 1 in 32 (one exception, 1 in 16). At the onset the majority of specimens were positive for EB IgM and heterophil

\begin{tabular}{llll}
\hline Test & HA & $\begin{array}{l}\text { Number of Sera } \\
\text { for Each Pattern }\end{array}$ \\
\cline { 1 - 2 } EB IgG & EB IgM & & \\
\hline- & - & - & 3 \\
- & - & + & 1 \\
+ & - & + & 1 \\
+ & + & - & 4 \\
+ & + & + & 6 \\
Total negative & 6 & 8 & 16 \\
\hline
\end{tabular}

Table I Variations in results of three tests at onset of confirmed infectious mononucleosis: pattern of results on 16 sera negative in at least one test

HA = heterophil antibody 

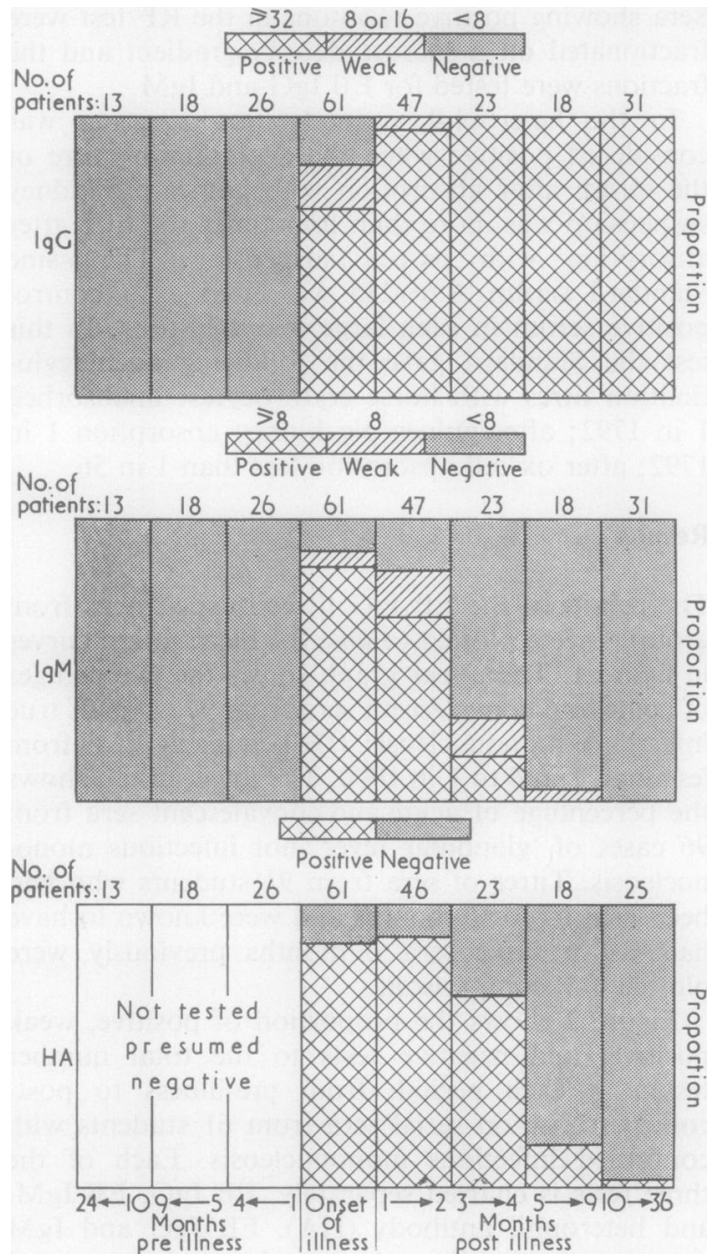

Fig 2 Results of EB IgG and IgM and heterophil antibody (HA tests) on sera from 61 cases of infectious mononucleosis from whom pre-illness, illness, and post-illness sera were obtained. A chart of the proportion positive, weak positive or negative of the number tested at each interval before or after onset of illness.

antibody but some were negative. Table I shows the pattern of results of negative tests occurring at onset. In three cases all the tests were negative at onset. All those cases negative for EB IgM and/or heterophil antibody at onset were positive in the convalescent specimen taken between one and two months later but some of the cases positive for EB IgM and HA at onset had already become negative by the convalescent specimen, and in the following months these two tests gradually became negative. More of the HA tests were positive between five and nine months later than were the EB IgM tests, and one was positive 13 months later.

\begin{tabular}{lll}
\hline EBVIgM & \multicolumn{2}{l}{ Heterophil Antibody } \\
\cline { 2 - 3 } & Positive & Negative \\
\hline Positive & 84 & 15 \\
Negative & 3 & 304 \\
\hline
\end{tabular}

Table II Group B 406 diagnostic specimens for heterophil antibody test: comparison of EBV IgM titre and $\mathrm{HA}$ result

It is known from absorption experiments with ox-cells. that these antibodies are directed to different antigens so the fading away would not be expectes? to coincide. In fact of the 22 sera found positive after three months, only two were positive in both tests.

The comparison of positive and negative resultso in EB IgM and heterophil antibody (HA) tests on the sera in group B is shown in table II. Of the 406 sero tested:

304 were negative in both tests

84 were positive in both tests

3 were negative in the EB IgM test but positive in the HA test

15 were negative in the $\mathrm{HA}$ and monospot test $\stackrel{\mathbb{S}}{\mathrm{s}}$ but positive in the EB IgM test (6 weakty) Of 100 acute and convalescent sera from 59 patiemt\$ with IM tested for rheumatoid factor, all specimeng from 42 students were negative, six students gave positive result in both specimens, and the pre-illnes? serum was also positive from four of these studentso Eleven gave a weak positive result in the acutis specimen only.

All the IM sera tested after density gradien fractionation from group A gave positive EB IgM staining in the macroglobulin fraction whether the presence of RF had been demonstrated or not. showing that in these cases specific EB IgM was alse present. Of the 15 sera in group B giving positive EB IgM and negative HA results, only four were. available for RF test because the other 11 had beem used up in repeating the EB IgM and HA tests. AlR four of these were strongly positive for RF, and after density gradient fractionation no specifis EB IgM staining could be demonstrated in the IgM fraction, indicating absence of EB specific IgM

Table III shows the distribution of strongs, negative, and weak EB IgG results in relation tof the HA results in the sera from group B. Fifty-one्E were negative. One of these was positive in HA and EB IgM consistent with an early infection, as in lines six of table I. Thirty-four sera were only weaklf positive, that is, with titres of 1 in 8 or 16 , and 2 ? of these were positive for EB IgM and HA. Witho the one serum mentioned above this means $24 \circ 6$ 87 HA positive cases (28\%) had negative or low 


\begin{tabular}{llcll}
\hline EBV IgG & Titre & Number & \multicolumn{2}{l}{ HA Result } \\
\cline { 3 - 5 } & & & Positive & Negative \\
\hline Positive & 32 or more & 321 & 67 & 254 \\
Weak positive & 8 or 16 & 34 & 24 & 10 \\
Negative & less than 8 & 51 & 1 & 50 \\
\hline
\end{tabular}

Table III Group B 406 diagnostic specimens for heterophil antibody test: comparison of EBV IgG titre and $\mathrm{HA}$ result

EB IgG titres and would probably have given a four-fold rise in titre if tested again at a later date. However, an interesting finding was that, when checking the final EB IgG titres of the sera reacting weakly at 1 in 8 , it was found that nine out of 24 sera positive in the HA test and IgM test gave stronger IgG reactions at 1 in 32 than at 1 in 8 . This suggests that some low readings in acute specimens may be due to a prozone phenomenon.

\section{Discussion}

There have been several studies of EBVCA IgG and IgM and heterophil antibody tests in possible cases of infectious mononucleosis (Nikoskelainen et al, 1974), indicating that a small proportion of such cases do not have a positive HA test even when using horse erythrocytes. Without pre-illness sera it is not possible to identify and exclude patients who are suffering from an illness resembling IM but who have a longstanding EB IgG titre due to an EB virus infection months or years earlier. A positive EB IgM may be present but can be accepted as evidence of recent infection with EB virus only if a false positive result due to RF has been excluded. Another difficulty is that patients are often admitted to hospital rather late in the disease when the HA may already have become negative. Conversely, if the patient is seen very early in the disease, as were our students, the HA test may be negative and should be repeated later.

In our university study from 193 suspect cases we had 96 mimicking IM. Because we tested a pre-illness serum we were able to show that of these cases 60 had had EB IgG before illness and 36 had no EB IgG either before or after illness. The illness of these 96 was therefore not IM. Furthermore, bacterial and viral studies on the acute and convalescent sera of these cases indicated an alternative diagnosis in 29 and a probable diagnosis in a further three (table IV). The other 97 suspect cases all showed full criteria of infectious mononucleosis, and in all of these EB IgM was detected.

The EB IgG titres of the 193 suspect student cases and the healthy students show that $43 \%$ of acute

\begin{tabular}{ll}
\hline Agent & $\begin{array}{l}\text { Number of Positive } \\
\text { Cases }\end{array}$ \\
\hline Group A streptococcus & 12 \\
Rubella virus & $10^{1}$ \\
Herpes simplex virus & 4 \\
Adenovirus & 2 \\
Cytomegalovirus & 2 \\
Parvovirus & 2 \\
Total & 32 \\
\hline
\end{tabular}

Table IV 32 alternative serological diagnoses in the 96 NON-IM cases

${ }^{1}$ One reaction to rubella vaccine

specimens from the IM cases ranged from less than 1 in 8 to 1 in 16. Both the students and health physicians were on the alert for the disease so first specimens were taken very soon after onset. In all but one of these cases the convalescent specimen revealed a four-fold rise in titre. Of the 96 cases who did not have IM, 37\% had no EB IgG at a dilution of 1 in 8 either at onset or in convalescence. By titrating paired specimens, therefore, the diagnosis could have been confirmed or excluded in $40 \%$ of the 193 suspect cases. On the other hand, the same conclusion could have been reached from the heterophil antibody test results.

When the cases which were EB IgG negative in both acute and convalescent specimens are removed from the graph of heterophil antibody negative cases it will be found that the percentage curves calculated for the remaining $60 \mathrm{~EB}$ IgG positive cases approximate to those of the convalescent IM cases and the healthy students. In the latter there is a preponderance of titres of 1 in 128 . This may be a genuine phenomenon but deviation to 1 in 64 or 256 is within the experimental error of the test. These curves indicate that an EB IgG titre in the range 1 in 32 to 1 in 512 in our test in a single specimen of serum is uninformative as this range of titres is common to healthy students, non-IM cases and convalescent IM cases alike. It is important to remember that the scale of titre varies from laboratory to laboratory largely because of differing techniques and optical equipment (Geser et al, 1974). Each laboratory therefore has to set its own normal distribution curve. However, if the titre of the Standard serum described and the method of reading were quoted with the work of each laboratory useful comparisons could be made.

Close agreement is shown between the HA and EB IgM tests (table II) on the $\mathbf{4 0 6}$ sera of group B. The time in relation to onset of these sera is not known; possibly the sera which are not concordant could be very early or late specimens, times when of the two only one may be positive. The tests for rheumatoid factor, which revealed four false 
positive EB IgM results confirmed by tests after density gradient fractionation, explain some if not all the EB IgM positive results in the absence of HA. The ages of two of these patients were known and they were over 40 years of age.

It has been said repeatedly that in cases of infectious mononucleosis under the age of 10 the HA tests are often not positive. However, in our group B sera we did not find any from this age group positive for EB IgM and negative for $\mathrm{HA}$ so we have no evidence to support this statement. Unfortunately the ages of only 212 of the $\mathbf{4 0 6}$ patients in group B were known, and the accurate date of onset of illness was rarely available. Of those 212 whose age was known, only $27(13 \%)$ were under 10 years of age. This means either that IM-like illness is uncommon or that doctors are disinclined to take blood specimens at that age.

The sera of nine of these 27 were negative in all tests. These children had either never had an EB infection or were very early cases. The sera from six were positive in all three tests, showing that at least some EB infections under 10 years have an illness resembling infectious mononucleosis and with an HA response. Twelve sera were positive only for EB IgG and were therefore from children with a past infection with EB virus or who were late cases from whose sera the other antibodies had already disappeared. They are unlikely to have been very early cases as, from the student figures (line 3 of table I), only 1 in 61 had only an EB IgG test positive at onset. EB IgM and HA tests on sera taken from small children for other laboratory investigations might reveal the clinical pattern associated with EB infection and show whether a positive HA test is indeed often absent when EB virus infection occurs at an early age. It is possible that it may often be asymptomatic as positive EB IgM and HA tests have been found in sera from students taken during routine sampling when no recent illness has been reported (PHLS unpublished and Sutton et al, 1974b).

It is concluded that the diagnosis of IM can be confirmed or excluded by performing EB IgG titres in parallel on early and late sera from those cases whose test at onset is negative at 1 in 8 or less than 1 in 32. A further negative test excludes EB infection, and a four-fold or greater rise in titre confirms current EB infection. High titres can persist so long that high titres in a single serum or pair of sera cannot be valuable either in confirming or excluding recent EB infection.

The EB IgM test can sometimes confirm current infection but false positive tests due to rheumatoid factor must be excluded.

The horse erythrocyte heterophil antibody test remains the most useful diagnostic test in infectiou mononucleosis but reliance should not be made on $\mathrm{q}$ single negative test. Confirmation of the clinicat diagnosis of infectious mononucleosis by $\mathrm{HA}$ at the time of illness is very valuable as the significance $\overline{\text { F }}$ possible relapses or other following lymphoprolife ative disorders can be assessed more readily if the time of primary infection with EB virus is know with certainty.

The unversity investigation was organized by the Epidemiology Research Laboratory and we wish to thank the University Health Physicians and M G. V. Smith who provided the blood samples and records. We also wish to thank The Wellcomis Research Laboratories for providing the specifif anti-human IgG/FITC conjugate for the immunio fluorescence test; Miss Jordan, of the Centrat Middlesex Microbiology Institute, for the heterophg antibody testing, and Mrs Joy, of the Virus Reference Laboratory, and Mrs Adams, of the Photographif Department, for help in preparing this report.

\section{References}

Banatvala, J. E., Best, J. M., and Waller, D. K. (1972) Epstein-Barr virus-specific IgM in infectious mone nucleosis, Burkitt lymphoma, and nasopharyngeal eap cinoma. Lancet, 1, 1205-1208.

Davidsohn, I. and Henry, J. B., Eds. (1969). Todd-Satisid Clinical Diagnosis by Laboratory Methods, 14th Saunders, Philadelphia.

Edwards, J. M. B. and McSwiggan, D. A. (1974). Studies of the diagnostic value of an immunofluorescence test for EB virus-specific IgM. J. clin. Path., 27, 647-651.

Geser, A., Day, N. E., de-The, G. B., Chew, B. K., Freun R. J., Kwan, H. C., Lavoue, M. F., Simkovic, D., any Sohier, R. (1974). The variability in immunofluorescent viral capsid antigen antibody tests in population survey of Epstein-Barr virus infections. Bull. Wld Hlth Org., 50 . 389-400.

Hampar, B., Hsu, K. C., Martos, L. M., and Walker, J. (1971). Serologic evidence that a herpes-type virus is the etiologic agent of heterophile-positive infectious mono 3 . nucleosis. Proc. nat. Acad. Sci. (Wash.), 68, 1407-1411. ஷे

Henle, G. and Henle, W. (1966). Immunofluorescence i cells derived from Burkitt's lymphoma. J. Bact., 91, 1248-1256.

Niederman, J. C., Evans, A. S., Subrahmanyan, L., angु McCollom, R. W. (1970). Prevalence, incidence anto persistence of EB virus antibody in young adults. Ne Engl. J. Med., 282, 361-365.

N

Nikoskelainen, J., Leikola, J., and Klemola, E. (1974). IgN antibodies specific for Epstein-Barr virus in infectious mononucleosis without heterophil antibodies. Brit. med. J N 4, 72-75.

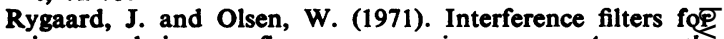
improved immunofluorescence microscopy. Acta pat tho microbiol. scand., 76, 146-148.

Schmitz, H. and Scherer, M. (1972). IgM antibodies t $\bar{\Phi}$ Epstein-Barr virus in infectious mononucleosis. Arch. ges. Virusforsch., 37, 332-339.

Sumaya, C. V., Henle, W., Henle, G., Smith, M. H. D., an $\Phi$ Le Blanc, D. (1975). Seroepidemiologic study of Epsteing 
Barr virus infections in a rural community. J. infect. Dis., 131, 403-408.

Sutton, R. N. P., Emond, R. T. D., Thomas, D. B., and Doniach, D. (1974a). The occurrence of autoantibodies in infectious mononucleosis. Clin. exp. Immunol., 17, 427-436. Sutton, R. N. P., Marston, S. D., Almond, E. J. P., Reynolds,
K., and Pounds, F. J. (1974b). Asymptomatic infection with EB virus. J. clin. Path., 27, 97-100.

University Health Physicians and Public Health Laboratory Service Laboratories (1971). Infectious mononucleosis and its relationship to EB virus antibody. Brit. med. J., 4, 643-646.

\section{Reports and Bulletins prepared by the Association of Clinical Biochemists}

The following reports and bulletins are published by the Association of Clinical Biochemists. They may be obtained from The Publishing Department, British Medical Journal (ACB Technical Bulletins), B.M.A. House, Tavistock Square, London WC1H 9JR. Overseas readers should remit by British Postal or Money Order.

SCIENTIFIC REPORTS (price $£ 1 \cdot 00 / \$ 2.00$ each)

3 Automatic Dispensing Pipettes: an assessment of 35 commercial instruments September 1967 P. M. G. BROUGHTON, A. H. GOWENLOCK, G. M. WIDDOWSON, and K. A. AHLQUIST

4 An Evaluation of five Commercial Flame Photometers suitable for the Simultaneous Determination of Sodium and Potassium March 1970 P. M. G. BROUGHTON and J. B. DAWSON

SCIENTIFIC REVIEWS (price $£ 1 \cdot 00 / \$ 2.00$ each)

1 The Assessment of Thyroid Function March 1971 F. V. FLYNN and J. R. HOBBS

2 Renal Function Tests Suitable for Clinical Practice January 1972 F. L. MITCHELL, N. VEALL, and R. W. E. WATTS

3 Biochemical Tests for the Assessment of Fetoplacental Function May 1975 C. E. WILDE and R. E. OAKEY

TECHNICAL BULLETINS (price $£ 1.00 / \$ 2.00$ each)

9 Determination of Urea by AutoAnalyzer November 1966 RUTH M. HASLAM

11 Determination of Serum Albumin by AutoAnalyzer using Bromocresol Green October 1967 B. E. NORTHAM and G. M. WIDDOWSON

13 An Assessment of the Technicon Type II Sampler Unit March 1968 B. C. GRAY and G. K. MCGOWAN

14 Atomic Absorption Spectroscopy: an outline of its principles and a guide to the selection of instruments May 1968 J. B. DAWSON and P. M. G. BROUGHTON

15 A Guide to Automatic Pipettes (2nd edition) June 1968 P. M. G. BROUGHTON

16 A Guide to Automation in Clinical Chemistry May 1969 P. M. G. BROUGHTON

17 Flame Photometers: a comparative list of 17 instruments readily available in Britain August $1969 \mathrm{P}$. WILDING

19 Spectrophotometers: a comparative list of low-priced instruments readily available in Britain May 1970 C. E. WILDE and P. SEWELL
20 Quantities and Units in Clinical Biochemistry June 1970 P. M.'G. BROUGHTON

21 Filter Fluorimeters: A comparative list of 18 instruments September 1970 H. BRAUNSBERG and s. S. BROWN 22 Bilirubin Standards and the Determination of Bilirubin by Manual and Technicon AutoAnalyzer Methods January 1971 BARBARA BILLING, RUTH HASLAM, and N. WALD

23 Interchangeable Cells for Spectrophotometers and Fluorimeters September 1971 S. S. BROWN and A. H. GOWENLOCK

24 Simple Tests to Detect Poisons March 1972 B. W. MEADE et al.

25 Blood Gas Analysers May 1972 K. DIXoN

26 Kits for Enzyme Activity Determination September 1972 S. B. ROSALKI and D. TARLOW

27 Assessment of Pumps Suitable for Incorporation into Existing Continuous Flow Analytical Systems November 1972 A. FLECK et al.

28 Routine Clinical Measurements of Transferrin in Human Serum September 1973 K. DIXON

29 Control Materials for Clinical Biochemistry (5th edition) September 1973 J. F. STEVENS

30 Notes on the Quality of Performance of Serum Cholesterol Assays September 1973 s. S. BROWN

31 Determination of Uric Acid in Blood and in Urine July 1974 R. W. E. WATTS

32 A Survey of Amino Acid Analysers Readily Available in the United Kingdom September 1974 J. E. CARLYLE and P. PURKISS

33 Definitions of some Words and Terms used in Automated Analysis November 1974 A. FLECK, R. ROBINSON, S. S. BROWN, and J. R. HOBBS

34 Measurement of Albumin in the Sera of Patients January 1975 LINDA SLATER, P. M. CARTER, and J. R. HOBBS

35 Investigation of the Validity of Temperature Correction Factors for Serum Aspartate and Alanine Transaminases March 1975 S. B. ROSALKI et al.

36 Factors Influencing the Assay of Creatinine November 1975 J. G. H. COOK 